\title{
Level of fatigue and daytime sleepiness among heavy vehicle drivers in Sri Lanka
}

\author{
Damitha Asanga Gunawardane ${ }^{1}$, Samath D Dharmaratne ${ }^{2}$
}

\begin{abstract}
${ }^{1}$ Trainee in MD Community Medicine, Department of Community Medicine, Faculty of Medicine, University of Peradeniya. Sri Lanka. ${ }^{2}$ Associate Professor in Community Medicine and Consultant Community Physician, Department of Community Medicine, Faculty of Medicine, University of Peradeniya. Sri Lanka.
\end{abstract}

\begin{abstract}
Heavy vehicle crash rates are high in Sri Lanka. International studies showed that fatigue and day time sleepiness are linked to heavy vehicle crashes. The aim of this study is to examine the level of fatigue, day time sleepiness and their associated factors among heavy vehicle drivers in Sri Lanka. A descriptive cross-sectional study was carried out in 403 heavy vehicle drivers through an interviewer administered structured questionnaire consisting of the 'Fatigue Severity Scale' (FFS) and the 'Epworth Sleepiness Scale' (ESS). The mean age of the study sample was $36.5 \pm 8.6$ years and all were males. They drive an average of $129.03 \pm 87.24 \mathrm{~km} /$ day. It was found that the mean FFS score in the study participants was $2.43 \pm 0.99$ and the mean ESS score was $6.57 \pm 4.07$. Prevalence of fatigue (FSS score $\geq 4)$ was $8.7 \%(n=35)$ and the prevalence of excessive day time sleepiness (EDS) (ESS score $>10)$ was $14.4 \%$ $(\mathrm{n}=58)$. Working for non-fixed schedule, married marital status, and working more than 11 hours/day are found to be significant risk factors for being fatigue. Drivers who were having night sleep of less than 6 hours were found to have a higher risk of EDS. A high prevalence of fatigue (8.7\%) and EDS (14.4\%) among heavy vehicle drivers was found which may link to heavy vehicle crashes. The occupational health service providers should be aware of the possibility of fatigue and daytime sleepiness in heavy vehicle drivers and its overall risk on the roads to take necessary actions.
\end{abstract}

Keywords: Fatigue, Excessive daytime sleepiness, Heavy vehicle drivers, Road traffic accidents, Sri Lanka.

\section{Introduction}

At present nearly 6 people die and 50 people get injured daily, from road traffic crashes in Sri Lanka. ${ }^{1}$ Compared to the crash rate of non-heavy vehicles, a higher rate was noted among heavy vehicles in Sri Lanka during last few years. ${ }^{2}$ Reasons for this difference in Sri Lanka were not studied. As reported by Gunawardane et al. ${ }^{1}$ Lorries and Private buses accounted for the highest proportions (48\% and $34 \%$ respectively) of heavy vehicle crashes in Sri Lanka. In another study done by Kumarage et al. ${ }^{3}$ a significant proportion of fatal road traffic crashes in Sri Lanka were associated with the fatigued condition of the driver.

Fatigue and sleepiness were found to be major contributing factors for heavy vehicle accidents in several studies conducted in other countries. In a survey done in United States it showed that $58 \%$ of road accidents in which only one heavy vehicle was involved, was linked to fatigue, in nearly $18 \%$ of cases the driver admitted that he had fallen asleep. ${ }^{4}$ Another survey done among 960 Australian drivers, $77.5 \%$ rated fatigue as at least a substantial problem and $50.6 \%$ reported feeling fatigue on their last trip. ${ }^{5}$ In similar US survey among long distance truck drivers, $47 \%$ had fallen asleep at the wheel at some time. ${ }^{6}$

As stated by Dobbie ${ }^{7}$ even though the phenomenon of fatigue is heavily researched it does not have a universally accepted definition. Grandjean ${ }^{8}$ defines fatigue as 'a gradual and cumulative process associated with a loss of

\section{Practice Points}

- Fatigue and sleepiness are found to be among the major contributing factors for heavy vehicle accidents in many countries.

- Prevalence of fatigue was $8.7 \%$ and the prevalence of excessive daytime sleepiness (EDS) was $14.4 \%$ among Sri Lankan heavy vehicle drivers.

- Working a non-fixed schedule, marital status, and working more than 11 hours per day are found to be significant risk factors for fatigue.

- Drivers who were having night sleep of less than 6 hours were found to have a higher risk of EDS.

- Further studies focusing on fatigue and sleep disorders in heavy vehicle drivers should be conducted and occupational health service providers should be aware of the possibility of fatigue and daytime sleepiness in heavy vehicle drivers and its overall risk on the roads for necessary action.

efficacy and a disinclination for any kind of effort'. According Hossain et al. ${ }^{9}$ fatigue is 'a state in which one's capacity or efficacy for work is reduced following physical and mental effort, it does not

Correspondence: Dr. Damitha Asanga Gunawardane, 17, Hansa Sevana, Sooriyagoda, Muruthalawa. Sri Lanka. 20232. Email: damithagunawardane@gmail.com. 
necessarily imply the irresistible desire for or tendency to fall asleep'.

When one considers "sleepiness", it signals the likelihood of falling asleep and it is defined as 'a difficulty in remaining awake'. ${ }^{10}$ Whereas daytime sleepiness has been defined by Johns and Hocking ${ }^{11}$ as 'the sense of the propensity to doze or fall asleep when intending to remain awake'.

Several independent studies have showed poor correlation between subjective fatigue and sleepiness scores, providing support for the concept of fatigue and sleepiness as two distinct and independent phenomena. $^{12,13}$

According to Jackson and others, ${ }^{10}$ when drivers are fatigued or sleepy, vigilance and alertness deteriorate, resulting in adverse changes in driving performance, including increased line crossing and poor speed control. As found by the same authors, commercial vehicle drivers have a higher risk of sleep-related crashes.

So the aim of this study is to describe the level of fatigue, daytime sleepiness and their associated factors, among heavy vehicle drivers attending the National Transport Medical Institute, Kandy, Sri Lanka.

\section{Materials and Methods}

A descriptive cross-sectional study was carried out among heavy vehicle drivers attending the National Transport Medical Institute, Kandy for the renewal of heavy vehicle driving licenses. A total of 403 heavy vehicle drivers were included in the study through nonrandom sequential sampling technique. Interviewer administered close-ended pre-coded questionnaire was used for data collection. This questionnaire consisted of two parts; part one included questions on the drivers' age, their years of professional driving experience, their types of employment, vehicle types driven, average workday lengths, average driving distances, driving during risk hours, and questions on the degree to which driver fatigue was perceived as a hazard to road safety. Part two consisted of Fatigue Severity Scale (FSS) ${ }^{13}$ and Epworth Sleepiness Scale (ESS), ${ }^{17}$ which were used to measure the level of fatigue and level of daytime sleepiness among the study participants. Prevalence of fatigue and Excessive Daytime Sleepiness (EDS), between groups were compared and tested for statistical significance by chi-square test and Fisher's exact test and correlations were tested by Spearman's rank correlation coefficient. A ' $p$ ' value of less than 0.05 was considered as statistically significant. Data was analysed with SPSS 17 statistical software. Ethical clearance for the study was obtained by the Ethics Review Committee of the Faculty of Medicine Colombo.

Fatigue Severity Scale (FFS)

The FSS is a self-administered questionnaire with 9 items. Those items investigate the level of fatigue in different situations during the past week. ${ }^{14}$ 'The FSS emphasizes functional impact of fatigue and contains items on physical, mental and social aspects, although these are not divided in explicit domains. Items are brief and easily understandable statements related to fatigue. These are rated on a seven-grade Likert scale. Grading of each item ranges from 1 to 7 , where 1 indicates strong disagreement and 7 strong agreements, and the final score represents the mean value of the 9 items. The total FSS score represents the mean score of each of the nine items, yielding a score range between 1 and 7 , higher scores indicating a higher level of fatigue'. ${ }^{15}$ An average score of 4 or more was considered as fatigue. ${ }^{14-}$ ${ }^{16}$ Developers of this tool, Krupp et al. ${ }^{17}$ believe that FSS is an 'useful in the evaluation of fatigue in both clinical research studies and surveys. Its brevity and simple self-report format make it a cost-effective alternative to more elaborate methods'. Even though this tool has not been used in earlier studies on drivers this has been used to measure the level of fatigue level among shift workers ${ }^{9}$ and also to measure fatigue level among women. ${ }^{14}$ Taylor et al. ${ }^{18}$ also stated that FSS is an 'appropriate and useful measures of fatigue-related symptomatology and disability within a general population of individuals with varying levels of fatigue'.

\section{The Epworth Sleepiness Scale (ESS)}

The Epworth Sleepiness Scale is a brief, selfadministered questionnaire with 8 questions which refers to the usual way of life in recent times of a person. 'It provides a measure of a person's general level of daytime sleepiness, or their average sleep propensity in daily life. The ESS asks people to rate, on a 4-point scale (0-3), their usual chances of dozing off or falling asleep in 8 different situations or activities that most people engage in as part of their daily lives, although not necessarily every day'. ${ }^{19}$ 'The total ESS score is the sum of 8 item-scores and can range between 0 and 24.The higher the score, the higher the person's level of daytime sleepiness'. ${ }^{19}$ A total score of more than 10 out of 24 may indicate Excessive Daytime Sleepiness, and may be indicative of a sleep disorder. ${ }^{20}$

\section{Results}

To obtain the required sample size, data collectors were conducted interviews and 403 questionnaires were completed.The mean age of study participants was 36.51 ( $\mathrm{SD}=8.61$ ) years ranging from 23 years to 77 years of age and All participants of this study were males. The mean BMI was $22.91 \mathrm{Kg} / \mathrm{m}^{2}$, which ranged from 16.30 to $38.75 \mathrm{Kg} / \mathrm{m}^{2}$ and $29 \%$ of participants were either overweight or obese. Proportion of drivers who were having $<5$ years driving experience was $23.6 \%(n=95)$. Socio-demographic work characteristics of the respondents are shown in Table 1.

The mean FSS score was $2.43(\mathrm{SD}=0.99)$ which ranged from 1.0 to 6.11 . As shown in Table 2 only $8.7 \%(n=35)$ of drivers had average FSS score of 4 or more, indicative of fatigue. Mean ESS Score was $6.57 \pm 4.07$ with a range of 0 to 19 . According to the ESS Scores obtained by heavy vehicle drivers in the study, $14.4 \%$ $(n=58)$ had scores higher than 10, indicating Excessive 
Table 1: Socio-demographic details of the respondents

\begin{tabular}{|l|c|c|}
\hline Variables & Frequency (\%) & Mean \pm SD \\
\hline Age (years) & & $36.5 \pm 8.61$ \\
\hline$<35$ & $184(45.7 \%)$ & \\
\hline $35-64$ & $215(53.3 \%)$ & \\
\hline$>64$ & $4(1.0 \%)$ & \\
\hline Marital status & & \\
\hline Married & $384(82.9 \%)$ & \\
\hline Single & $67(0.5 \%)$ & \\
\hline Separated & $2(0.5 \%)$ & \\
\hline Body mass index & 0 & \\
\hline$<18.5$ & $286(71.0 \%)$ & \\
\hline $18.5-<25$ & $97(24.1 \%)$ & \\
\hline $25-29.9$ & $20(5.0 \%)$ & \\
\hline$>30$ & $6(1.5 \%)$ & \\
\hline Chronic medical conditions (self-reported) & & \\
\hline Heavy vehicle driving experience & $95(23.6 \%)$ & \\
\hline$<5$ & $111(27.5 \%)$ & \\
\hline $5-9$ & $101(25.1 \%)$ & \\
\hline $10-14$ & $96(23.8 \%)$ & \\
\hline$>15$ & & \\
\hline Working hours per day & & \\
\hline Hours of driving per day & & \\
\hline Hours of continuous driving & $304(75.4 \%)$ & \\
\hline$<2$ & $86(21.4 \%)$ & \\
\hline $2-4.5$ & $13(3.2 \%)$ & \\
\hline$>4.5$ & & \\
\hline Working days per week & $115(28.5 \%)$ & \\
\hline 7 days & & \\
\hline Driving distance & $161(40 \%)$ & \\
\hline Driving to a fixed schedule (Yes) & & \\
\hline & & \\
\hline & & \\
\hline & & \\
\hline & & \\
\hline & & \\
\hline & & \\
\hline & & \\
\hline
\end{tabular}

\section{Daytime Sleepiness.}

Associated factors of fatigue and daytime sleepiness among study population

Table 2 shows the prevalence rates of EDS and Fatigue for some of risk factors analysed. Chi squared test was used to compare differences between prevalence rates. According to univariate analysis, working more than 11 hours per day and not working for fixed schedule were risk factors for fatigue, but only night sleep less than 6 hours was associated with the EDS out of the factors studied.

Independent risk factors for EDS and fatigue as determined from the multiple logistic regression analysis are listed in Table 3 . The strongest risk factor identified for fatigue was working for non-fixed schedule. Marital status (married) and working more than 11 hours per day also proved to be significant risk factors for fatigue. None of the risk factors become significant in multivariate analysis for EDS.

Associations between FSS and ESS Scores

Spearman's rho correlational coefficient, between FSS Scores and ESS Scores of heavy vehicle drivers in this study was 0.240 (p-0.001), indicating a statistically significant weak association.

\section{Perception of drivers on driver fatigue}

To assess the perception of drivers on driver fatigue as a hazard to road safety three questions were asked. As shown in Table 4, drivers who stated that tiredness or fatigue as a problem for themselves always or often while driving had a higher prevalence of EDS than drivers who rated as sometimes, rarely or never.

\section{Discussion}

The aim of this study was to describe the level of fatigue, daytime sleepiness and their associated factors among heavy vehicle drivers attending NTMI-Kandy. According to the findings considerable proportion of heavy vehicle drivers were found to be suffering from of the fatigue and excessive daytime sleepiness $(8.7 \%$ and $14.4 \%$ respectively).

Fatigue severity scale was used to measure the level of fatigue in this study. In several studies ${ }^{15,16}$ a mean FSS score of 4 or more was used to define fatigue. So in this study we also defined drivers as having fatigue if their mean FSS score was 4 or more. The time frame covering by FSS was not clearly mentioned in the original article ${ }^{17}$ but National Women's Health Resource Center ${ }^{14}$, use it as one week with the permission of the principal author (Prof. Lauren B Krupp). Same time 
Table 2: Prevalence of fatigue and EDS within risk factor groups on univariate analysis

\begin{tabular}{|c|c|c|c|}
\hline \multirow{2}{*}{ Risk factors } & \multirow[t]{2}{*}{ Respondents } & \multicolumn{2}{|c|}{ Prevalence } \\
\hline & & Fatigue n (\%) & EDS n (\%) \\
\hline Total population & 403 & $35(8.7 \%)$ & $58(14.4)$ \\
\hline \multicolumn{4}{|l|}{ Marital status } \\
\hline Married & 334 & $9.9(33 \%)$ & $15.0(50 \%)$ \\
\hline Unmarried & 67 & $2.9(2 \%)$ & $11.6(8 \%)$ \\
\hline \multicolumn{4}{|l|}{ Age (years) } \\
\hline$\leq 30$ & 184 & $8.3(9 \%)$ & $13.0(14 \%)$ \\
\hline$>30$ & 219 & $8.8(26 \%)$ & $14.9(44 \%)$ \\
\hline \multicolumn{4}{|c|}{ Heavy vehicle driving experience } \\
\hline$\leq 10$ & 230 & $9.4(24 \%)$ & $14.6(37 \%)$ \\
\hline$>10$ & 138 & $7.4(11 \%)$ & $14.1(21 \%)$ \\
\hline \multicolumn{4}{|l|}{$B M I$} \\
\hline$<30$ & 383 & $8.6(33 \%)$ & $14.1(54 \%)$ \\
\hline$\geq 30$ & 20 & $10.0(2 \%)$ & $20.0(4 \%)$ \\
\hline \multicolumn{4}{|l|}{ Workday length } \\
\hline$\leq 11$ & 288 & $6.6(19 \%)^{*}$ & $12.8(37 \%)$ \\
\hline$>11$ & 115 & $13.9(16 \%)$ & $18.3(21 \%)$ \\
\hline \multicolumn{4}{|l|}{ Hours of continuous driving } \\
\hline$\leq 2$ & 304 & $8.2(25 \%)$ & $14.8(45 \%)$ \\
\hline$>2$ & 99 & $10.1(10 \%)$ & $13.1(13 \%)$ \\
\hline \multicolumn{4}{|l|}{ Driving distance per day } \\
\hline$<200$ & 340 & $8.5(29 \%)$ & $13.8(47 \%)$ \\
\hline$>200$ & 63 & $9.5(6 \%)$ & $17.5(11 \%)$ \\
\hline \multicolumn{4}{|l|}{ Driver's night time sleep } \\
\hline$<6$ & 40 & $2.5(1 \%)$ & $25.0(10 \%)^{*}$ \\
\hline$>6$ & 363 & $9.4(34 \%)$ & $13.2(48 \%)$ \\
\hline \multicolumn{4}{|l|}{ Fixed schedule } \\
\hline Yes & 161 & $3.7(6 \%)^{*}$ & $15.5(25 \%)$ \\
\hline No & 242 & $12.0(29 \%)$ & $13.6(33 \%)$ \\
\hline
\end{tabular}

Table 3: Logistic regression results to assess the risk factors for fatigue and EDS

\begin{tabular}{|c|c|c|c|c|c|c|c|c|}
\hline \multirow[t]{3}{*}{ Variables } & \multicolumn{4}{|c|}{ Fatigue } & \multicolumn{4}{|c|}{ EDS } \\
\hline & \multirow{2}{*}{$\begin{array}{l}\text { Odds } \\
\text { Ratio }\end{array}$} & \multicolumn{2}{|c|}{$95 \%$ CI } & \multirow{2}{*}{$\begin{array}{l}\mathbf{P} \\
\text { value }\end{array}$} & \multirow{2}{*}{$\begin{array}{l}\text { Odds } \\
\text { Ratio }\end{array}$} & \multicolumn{2}{|c|}{$95 \%$ CI } & \multirow{2}{*}{$\begin{array}{l}P \\
\text { value }\end{array}$} \\
\hline & & Lower & Upper & & & Lower & Upper & \\
\hline $\begin{array}{l}\text { Age (years) } \\
(<=30 * />30)\end{array}$ & 0.84 & 0.32 & 2.20 & 0.728 & 1.15 & 0.51 & 2.62 & 0.733 \\
\hline $\begin{array}{l}\text { Marital status } \\
\text { (unmarried*/ married) }\end{array}$ & 5.43 & 1.16 & 25.43 & $0.032^{+}$ & 1.26 & 0.49 & 3.20 & 0.633 \\
\hline $\begin{array}{l}\text { BMI } \\
(<30 * / \geq 30)\end{array}$ & 1.43 & 0.29 & 7.18 & 0.662 & 1.48 & 0.46 & 4.75 & 0.509 \\
\hline $\begin{array}{l}\text { Work schedule } \\
\text { (fixed*/not fixed) }\end{array}$ & 3.97 & 1.55 & 10.15 & $0.004^{+}$ & 0.92 & 0.51 & 1.65 & 0.777 \\
\hline $\begin{array}{l}\text { Workday length } \\
(\leq 11 \mathrm{~h} * />11 \mathrm{~h})\end{array}$ & 2.33 & 1.07 & 5.09 & $0.033^{+}$ & 1.62 & 0.86 & 3.05 & 0.133 \\
\hline $\begin{array}{l}\text { Continuous driving } \\
(\leq 2 \mathrm{~h} * />2 \mathrm{~h})\end{array}$ & 0.81 & 0.32 & 2.04 & 0.650 & 0.59 & 0.27 & 1.29 & 0.188 \\
\hline $\begin{array}{l}\text { Driving distance/day }(\leq 200 * / \\
>200 \mathrm{~km})\end{array}$ & 1.46 & 0.50 & 4.26 & 0.492 & 1.50 & 0.66 & 3.42 & 0.332 \\
\hline $\begin{array}{l}\text { Night-time sleep } \\
\left(\geq 6^{*} /<6\right)\end{array}$ & 0.24 & 0.03 & 1.82 & 0.166 & 2.13 & 0.96 & 4.71 & 0.063 \\
\hline $\begin{array}{l}\text { Heavy vehicle driving experience } \\
(>10 \mathrm{yrs} * / \leq 10 \mathrm{yrs})\end{array}$ & 1.73 & 0.74 & 4.05 & .205 & 1.23 & 0.64 & 2.38 & 0.533 \\
\hline
\end{tabular}

South East Asia Journal of Public Health 2014;4(1):9-16 
Table 4: Relationship of driver fatigue problem rating with fatigue and EDS ( $n=403$ )

\begin{tabular}{|l|l|c|c|c|}
\hline \multicolumn{1}{|c|}{ Questions } & \multicolumn{1}{|c|}{ Rating } & N & Fatigue & EDS \\
\hline $\begin{array}{l}\text { Is tiredness or fa- } \\
\text { tigue a problem for } \\
\text { you when you } \\
\text { drive? }\end{array}$ & Always/Often & 38 & $10.5 \%$ & $28.9 \% * *$ \\
\cline { 2 - 5 } $\begin{array}{l}\text { Sometimes/Rarely/ } \\
\text { Do you think tired- } \\
\text { ness or fatigue is a } \\
\text { problem for other } \\
\text { drivers? }\end{array}$ & Always/Often & 365 & $8.5 \%$ & $12.9 \%$ \\
\cline { 2 - 5 } & $\begin{array}{l}\text { Sometimes/Rarely/ } \\
\text { Never }\end{array}$ & 259 & $10.4 \%$ & $20.1 \% *$ \\
\hline $\begin{array}{l}\text { Do you think tired- } \\
\text { ness or fatigue is } \\
\text { dangerous on the } \\
\text { road? }\end{array}$ & Always/Often & 218 & $1.7 \%$ & $11.2 \%$ \\
\cline { 2 - 5 } & $\begin{array}{l}\text { Sometimes/Rarely/ } \\
\text { Never }\end{array}$ & 285 & $7.0 \%$ & $11.4 \%$ \\
\hline $\begin{array}{l}\text { Differences between two groups * p }<0.05 * * p<0.01 \\
\text { EDS - Excessive Daytime Sleepiness }\end{array}$ & & \\
\hline
\end{tabular}

frame of one week also used in this study.

In the present study the mean FSS score of heavy vehicle drivers was $2.43(\mathrm{SD}=0.99)$. This was slightly higher than the mean FSS score of $2.3(\mathrm{SD}=0.7)$ for healthy adults, in the original study. ${ }^{17}$ Hossain et al. ${ }^{13}$ reported the mean FSS score of $2.2(\mathrm{SD}=0.5)$ for their least fatigue group. Nearly one in twelve $(8.7 \%, n=35)$ heavy vehicle drivers participated in this study was found to be fatigue (FSS $>4)$. This indicates that the fatigue is a significant problem in this study population.

To measure the day time sleepiness Epworth sleepiness scale was used. This tool is used to measure the level of day time in many studies ${ }^{21-24}$ done among heavy vehicle drivers. The mean ESS score of present sample of heavy vehicle drivers was $6.57(\mathrm{SD}=4.07)$. This was higher than the mean ESS score of $4.77(\mathrm{SD}=3.27)$ reported for lorry drivers in $\operatorname{Iran}^{21}$ and New Zealand (5.27; $\mathrm{SD}=3.67) .{ }^{23}$ However, the mean ESS score was found to be similar to a study ${ }^{25}$ done among 260 truck drivers in Brazil, which was $6.56(\mathrm{SD}=4.2)$. The ESS score more than 10 used to define excessive daytime sleepiness in this study as proposed by the developer of this tool. ${ }^{19}$ Same cutoff also used in several other studies. $^{11,21}$ Time frame in ESS was mentioned as in recent times' to judge the sleepiness in given situations. According to the developer (Dr. M. Jons) of this tool: 'It was a deliberate decision not to specify this time scale more accurately. It was intended to mean long enough for the subject to have experienced each situation referred to and to have formed an estimate of his/her chances of dozing in each. This may be a few weeks to a few months. ${ }^{19}$

Prevalence of EDS in the present study sample was $14.4 \%$, which is higher than the $9.1 \%$ as reported by Sadeghniat \& Labafinezhad, $^{21}$ in a sample of lorry drivers. When compared with the Iranian study ${ }^{21}$, the mean hours of driving per day in present study is well below the Iranian study $(11.56+3.70$ vs $4.58+2.06)$. Nearly one in seven drivers were having EDS (ESS $>10)$ indicating this was a significant problem for present study population.
As reported by Kaminska and others, ${ }^{26}$ the selfadministered ESS scores were higher than the scores given by the physician. Since this study was interviewer administered the ESS scores resulted might be lower than the self-rated ESS scores of this study sample.

As reported by Neu et $a l .{ }^{27}$ fatigue and sleepiness are two different phenomena. According to the same authors, these were used synonymously mainly in the studies, in which only one of these dimensions was studied. To support the above fact there were several studies which showed weak correlation between subjective fatigue assessed by FSS and subjective sleepiness assessed by ESS. ${ }^{12,13}$ Due to the above reasons, fatigue and sleepiness were considered as two distinct phenomena in this study. Results of the present study also revealed statistically significant weak association (Spearman's rho-0.240, $\mathrm{p}=0.001$ ). This further supports findings of previous studies. ${ }^{12,13}$ Both the scales in our study appear to be internally consistent as implied by cronbach's alpha 0.731 for FSS and 0.627 for ESS.

The mean age of the study sample was 36.51 years $(\mathrm{SD}=8.6)$. Therefore the heavy vehicle drivers in this study are younger than the drivers of the studies conducted by Sadeghniat \& Labafinezhad ${ }^{21}$ (43.23 years +9.72 ) and Souza et al. ${ }^{25}$ (38.2 years +10.6$)$.

Body Mass Index of the study participants ranged from 16.30 to $38.75 \mathrm{Kg} / \mathrm{m}^{2}$ and mean BMI was $22.91 \mathrm{Kg} / \mathrm{m}^{2}$ $(\mathrm{SD}=3.86)$. This was lower than drivers of the studies conducted in $\operatorname{Iran}^{21}\left[\mathrm{n}=386 ; 26.37 \mathrm{Kg} / \mathrm{m}^{2}(\mathrm{SD}=3.88)\right]$ and in Brazil $^{25}\left[\mathrm{n}=260 ; 27.64 \mathrm{Kg} / \mathrm{m}^{2}(\mathrm{SD}=4.34)\right]$. But the mean BMI of the study was higher than the mean BMI of $21.1 \mathrm{Kg} / \mathrm{m}^{2}(\mathrm{SD}=0.2)$ for men in Sri Lankan study $^{28}$ done among 4532 adults (using multi-stage random cluster sampling technique). According to the WHO international guidelines on $\mathrm{BMI},{ }^{29} 29.1 \%$ of heavy vehicle drivers in this study were either overweight or obese. A Similar finding was reported by Katulanda et $a l .{ }^{28}$ in their study on prevalence of overweight and obesity in Sri Lankan adults. According to the findings of this study obesity is not significantly 
associated with fatigue or EDS.

In our study, marital status (married), proved to be significant risk factor for fatigue but not for the EDS. However, study conducted by Nugent et al. ${ }^{30}$ in Northern Ireland reported married status as a risk factor for EDS.

Mean years of experience in heavy vehicle driving in this study was 10.13 years $(\mathrm{SD}=9.11)$. This is lower than, 16.06 years $(\mathrm{SD}=10.19)$ of Iranian lorry drivers ${ }^{21}$ and 13.31 years $(\mathrm{SD}=10.14)$ of New Zealand truck drivers. ${ }^{23}$ In the present study, it was found that nearly one fourth $(23.6 \%)$ of the drivers had less than 5 years of experience in heavy vehicle driving. This also supports the fact that present study sample is less experience in heavy vehicle driving. Being a less experience driver increase the likelihood of crashing. ${ }^{31}$

The mean workday length of this sample of drivers was 9.37 hours $(\mathrm{SD}=2.25)$. This was lower than the average workday length of 11.89 hours $(\mathrm{SD}=1.683)$ reported in a study among 600 New Zealand truck drivers. ${ }^{32}$ Hartley $^{33}$ reported that accident risk increased substantially after 11 hours of work. Results of this study also showed a statistically significant difference in prevalence of fatigue between drivers who work $<11$ hours and $>11$ hours $(\mathrm{X} 2=5.546, \mathrm{df}=1, \mathrm{p}=0.01)$. Therefore workday length more than 11 hours has to be considered as a risk factor for being fatigue.

The mean hours of driving per day in this study was 4.58 hours $(\mathrm{SD}=2.06)$. This was much lower than the 11.56 hours $(\mathrm{SD}=3.7)$ reported in Iranian lorry drivers ${ }^{21}$. In that study $76.2 \%$ of drivers drove more than 8 hours per day compared to $3.0 \%$ in this study. In the present study $60 \%$ of the drivers were not on fixed schedule and more importantly working for non-fixed schedule is identify as the strongest risk factor for being fatigue in the present study.

The majority of heavy vehicle drivers in this study drove 2 or less hours continuously without a break. This is a good counter measure to prevent fatigue or sleep related crashes. ${ }^{31,34}$ In this study investigator consider two or more periods of time as continuous period unless separated by an interval of half an hour as defined in Motor Traffic Act. ${ }^{35}$ Only $3.5 \%(n=13)$ of drivers had exceeded the legal continuous driving period of $4 \frac{1}{2}$ hours.

Based on the evidence fatigue expert group ${ }^{36}$ agreed the minimum sleep of six continuous hours per twenty four hours. Heavy vehicle drivers in this study had a mean night time sleep of 7.10 hours $(\mathrm{SD}=1.318)$. This is higher than the value of 6.85 hours $(\mathrm{SD}=1.20)$ found in Iranian lorry driver's study ${ }^{21}$ and 5.97 hours $(\mathrm{SD}=1.47)$ as reported by Souza et al. ${ }^{25}$ in their study among truck drivers in Brazil. In Brazil truck driver's study $23.8 \%$ of drivers slept less than 5 hours. But in present study only $9.9 \%$ of drivers had average night time sleep less than 5 hours. In this study statistically significant higher prevalence of EDS was observed among drivers who were having night sleep less than 6 hours compared to drivers who were having night sleep of 6 hours or more. This implies that night sleep less than 6 hours is associated with EDS.

In the study conducted by Charlton and others ${ }^{23}$ among truck drivers in New Zealand $34.8 \%$ rated fatigue as being a problem for other drivers always and often, whereas only $2.1 \%$ rated fatigue as often a problem for themselves. However, $88.5 \%$ of the drivers believed that fatigue was always dangerous on road. In the present study $35.8 \%$ rated fatigue as being a problem for other drivers always and often, and $9.4 \%$ rated fatigue as often a problem for themselves. But, only $22.1 \%$ of the drivers believed that fatigue was always dangerous on road. This indicates the poor knowledge of heavy vehicle drivers in this study on driver fatigue. Higher prevalence of fatigue and EDS was observed among drivers who stated tiredness or fatigue as a problem for themselves and other drivers than who do not stated it as a problem. This difference in the prevalence of EDS was statistically significant.

There are few limitations of the present study need to be taken in to account. Firstly, data collected in study were retrospective and subjective so recall bias and information bias were unavoidable. Sampling of this study was done through a non-random sequential sampling method, but this may not represent adequately the study population. Finally, the environment, within which the data were collected is somewhat threatening, due to the fact that majority of heavy vehicle drivers are depend on their medical certificate for their livelihoods. But this could not have influenced the study findings, as it was told that the findings will be kept confidential.

\section{Conclusion}

High prevalence of fatigue and EDS were found among Sri Lankan heavy vehicle drivers. Further studies focusing on fatigue and sleep disorders in heavy vehicle drivers should be conducted and occupational health service providers should be aware, of the possibility of fatigue and daytime sleepiness in heavy vehicle drivers and its overall risk on the roads, for necessary action.

\section{Acknowledgement}

We thank all the staff members of the National Transport Medical Institute, Kandy for the support given by them to conduct this study.

\section{References}

1. Gunawardane D, Dharmaratne S. Pattern of Road Traffic Crashes in Sri Lanka from 2006 to 2009; $J$ Sri Lankan Coll Community Physicians 2013;18:33-4.

2. Gunawardane DA; Dharmarathne SD. Heavy vehicle crashes in Sri Lanka, Proccedings of Conference on heavy vehicle crashes in Sri Lanka, 2012, p.68.

3. Kumarage AS, Abeygoonawardena CR, Wijesundera R. Identification of causal factors of 
traffic accidents in Sri Lanka. Colombo: Institution of Engineers (IESL), 2000.

4. National Transportation Safety Board Factors that affect fatigue in heavy truck accidents. Vol. 1. Analysis. Washington DC, 1995.

5. Williamson AM, Feyer AM, Coumarelos C, Jenkins T. Strategies to combat fatigue in the long distance road transport industry. Stage 1: The industry perspective, 1992.

6. McCartt AT, Rohrbaugh JW, Hammer MC, Fuller SZ. Factors associated with falling asleep at the wheel among long-distance truck drivers, Accid Anal Prev 2000;32:493-504.

7. Dobbie K. Fatigue-related crashes: An analysis of fatigue-related crashes on Australian roads using an operational definition of fatigue, 2002.

8. Grandjean E. Fatigue in industry. $B r J$ Ind Med. $1979 ; 36: 175-86$

9. Hossain JL, Reinish LW, Kayumov L, Bhuiya P, Shapiro CM. Underlying sleep pathology may cause chronic high fatigue in shift-workers. $J$ Sleep Res 2003;12: 223-30.

10. Jackson P, Hilditch C, Holmes A,Reed N, Merat N Smith L. Findings: Road Safety - fatigue and road safety: a critical analysis of recent evidence. London, 2011.

11. Johns M, Hocking B. Daytime sleepiness and sleep habits of Australian workers. Sleep 1997;20:844-9.

12. Shen J, Botly LC, Chung SA, Gibbs AL, Sabanadzovic S, Shapiro CM. Fatigue and shift work, J Sleep Res 2006; 15:1-5.

13. Hossain JL, Ahmad P, Reinish LW, Kayumov L, Hossain NK, Shapiro CM. Subjective fatigue and subjective sleepiness: two independent consequences of sleep disorders? J Sleep Res 2005; 14:245-53.

14. National Women's Health Resource Center Fatigue Severity Scale (FSS). http:// www.healthywomen.org/content/article/fatigueseverity-scale-fss (accessed July 2014)

15. Friedman JH, Alves G, Hagell P, et al. Fatigue rating scales critique and recommendations by the Movement Disorders Society task force on rating scales for Parkinson's disease Mov Disord 2010;25:805-22.

16. On AY, Oncu J, Atamaz F, Durmaz B. Impact of post-polio-related fatigue on quality of life. $J$ Rehabil Med 2006;38:329-32.

17. Krupp LB, LaRocca NG, Muir-Nash J, Steinberg AD. The fatigue severity scale. Application to patients with multiple sclerosis and systemic lupus erythematosus. Arch Neurol 1989;46:1121-3.
18. Taylor RR, Jason LA, Torres A. Fatigue rating scales: an empirical comparison. Psychol Med 2000;30:849-56.

19. Johns, M. The Epworth Sleepiness Scale. http:// epworthsleepinessscale.com/about-epworthsleepiness/(accessed July 2014)

20. Johns MW. A new method for measuring daytime sleepiness: the Epworth sleepiness scale. Sleep 1991;14:540-5.

21. Sadeghniat K, Labafinezhad Y. Sleepiness Among Iranian Lorry Drivers. Acta Med Iran 2007; 45:149-52.

22. Williamson A, Feyer AM, Friswell R, Sadural S. Driver Fatigue: A survey of long distance heavy vehicle drivers in Australia. Report 198, 2001.

23. Charlton SG, Baas PH, Alley BD, Luther RE. Analysis of fatigue levels in New Zealand Taxi and local-route truck drivers. In Transport Engineering New Zealand/Road Safety Trust, 2003.

24. Stutts JC, Wilkins W, Vaughn BV. Why do people have drowsy driving crashes. Input from drivers who just did. Washington DC, 1999.

25. Souza JC, Paiva T, Reimão R. Sleep habits, sleepiness and accidents among truck drivers. Arq Neuropsiquiatr 2005;63:925-30.

26. Kaminska M, Jobin V, Mayer P, Amyot R, Perraton-Brillon M, Bellemare F. The Epworth Sleepiness Scale: Self-administration versus administration by the physician, and validation of a French version. Can Respir J 2010;17:e27.

27. Neu D, Mairesse O, Hoffmann G, et al. Do 'sleepy' and 'tired' go together? Rasch analysis of the relationships between sleepiness, fatigue and nonrestorative sleep complaints in a nonclinical population sample. Neuroepidemiology. 2010;35:1-11

28. Katulanda P, Jayawardena MA, Sheriff MH, Constantine GR, Matthews DR. Prevalence of overweight and obesity in Sri Lankan adults Obes Rev 2010;11:751-6.

29. WHO Expert consultation. Appropriate bodymass index for Asian populations and its implications for policy and intervention strategies. Lancet 2004;363:157.

30. Nugent AM, Gleadhill I, McCrum E, Patterson CC, Evans A, MacMahon J. Sleep complaints and risk factors for excessive daytime sleepiness in adult males in Northern Ireland. $J$ Sleep Res 2001;10:69-74.

31. Stevenson MR, Elkington J, Sharwood L, Meuleners L, Ivers R, Boufous S, et al. The role of sleepiness, sleep disorders, and the work environment on heavy-vehicle crashes in 2 
Australian states. Am J Epidemiol 2014;179 (5):594-601.

32. Baas PH, Charlton SG, Bastin GT. Survey of New Zealand truck driver fatigue and fitness for duty. Transp Res Part F Traffic Psychol Behav 2000;3:185-93.

33. Hartley LR, Feyer AM. Comprehensive review of fatigue research Western Australia, 2001.

34. Drowsydriving.org. http:// drowsydriving.org/2011/11/national-sleepfoundation $\% \mathrm{E} 2 \% 80 \% 99 \mathrm{~s}$-drowsy-drivingprevention-week $\% \mathrm{C} 2 \% \mathrm{AE}$-provides-tips-toprevent-one-in-six-traffic-fatalities/ (accessed July 2014)
35. The Motor traffic (amendment) Act. S 2009/08. Colombo: The Government Publications Bureau, 2009.

36. Dawson D, Feyer A, Grander P, Hartley L, Haworth N, Williamson A. Options for regulatory approach to fatigue in drivers of heavy vehicles in Australia and New Zealand. Discussion paper from the Fatigue Expert Group. Australian Transport Safety Bureau (ATSB), 2001. 